\title{
SEMICONDUCTOR LASERS BASED ON QUANTUM WELL STRUCTURES
}

We present electrical and optical properties of the quantum well laser structures based on InAs / $A l_{x} G a_{1-x} A s$ material systems. The experimental results obtained from room- and low temperature electroluminescence measurements of InAs $/ A_{0.40} G a_{0.60} A s$ revealed the excellent emission spectra in the visible range 620-660 $\mathrm{nm}$. The experimentally obtained transitions energies were compared with simple Kronig-Penney simulations. Going to low temperatures the stimulated emission from the cleaved edge was observed, which could be real perspective for laser applications.

\section{Introduction to quantum structures}

The development of III-V semiconductor growth techniques and their ability for growth of smooth ultra-thin layers on atomic scale have opened a new area in semiconductor research and technology. Quantum well (QW) heterostructures and superlattices with high-quality crystal perfection were fabricated by molecular-beam epitaxy (MBE), or metal-organic vapor phase epitaxy (MOVPE) [1]. These QW structures prepared from various III-V alloy semiconductors have received considerable interest because of their band-energy variability, which allows preparing of optoelectronic devices operated in wide spectral range.

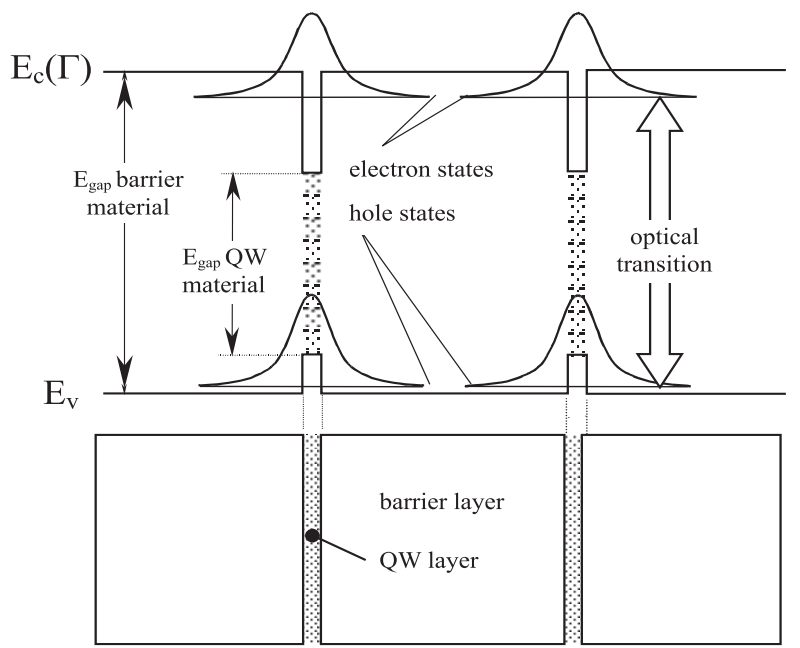

Fig. 1 Schematic of energy band diagram of $Q W$ structure $-Q W$ and barrier layer in active region. To form the potential quantum well the appropriate semiconductor material should be chosen $\left(E_{\text {gap }}(Q W)<E_{\text {gap }}\right.$

(barrier)). Electron and hole in $Q W$ are then localized above conduction and valence band edge, respectively. The energy of optical transition lies at higher energies than in bulk $Q W$ material.
In these structures the energy of optical transition can be adjusted by an appropriate choice of III-V alloy semiconductors as well as by layer thickness in active region (fig. 1) [2, 3].

Considerable attention has been recently devoted to monolayer (ML) and submonolayer QW structures with layer thickness of some atomic layers in active region [4, 5, 6]. In ML QW structures the electron and hole states are energetically localized close to the band edge of barrier layer. To improve emission intensity from active region the multi quantum well (MQW) structures were designed. For our studies the InAs material for $\mathrm{QW}$ and $\mathrm{Al}_{\mathrm{x}} \mathrm{Ga}_{1-\mathrm{x}} \mathrm{As}$ ternary as barrier material has been chosen. The $\mathrm{Al}$ mole fraction $x=0.40$ was used to achieve the emission at higher energy in comparison with the laser structure $x=0.34$ published in [7].

Our experimental investigations focus on characterization of optical and electrical properties at room and low temperatures. Electrical properties of the structure are investigated by the measuring of conventional current-voltage characteristics. Optical properties are characterized by photoluminescence $(P L)$ and electroluminescence $(E L)$ measurements. To get information on the layer perfection high-resolution transmission electron microscopy (HRTEM) investigations have been performed.

\section{Theoretical modeling of energy states}

For design of devices and comparison of experimental results with theory it is important to know the location of the lowest energy state of electrons $(e)$ in conduction band $(C B)$, heavy holes $(h h)$ and light holes $(l h)$ in valence band $(V B)$ (Fig. 2).

These states can be determined by solving Schrödinger's equation in each layer and by matching the solutions across the boundaries. As an idealized approximation for calculating the lowest $e$, $h h$ and $t h$ energy bands is the Kronig-Penney analysis [8]. These

\footnotetext{
* ${ }^{1}$ D. Pudiš, J. ${ }^{2}$ Kováč jr., ${ }^{3}$ J. Kováč, ${ }^{3}$ J. Jakabovič

${ }^{1}$ University of Žilina, Department of Physics, Vel'ký diel, SK 01026 Žilina, Slovakia

${ }^{2}$ International Laser Center, Ilkovičova 3, SK 81219 Bratislava, Slovakia

${ }^{3}$ Slovak Technical University, Department of Microelectronics, Ilkovičova 3, SK 81219 Bratislava, Slovakia
} 
calculations are simplified, but they provide a useful guide for choosing layer thickness corresponding to the desired $e, h h, l h$ energies. The $n=1$ energies are calculated as a function of well size for InAs and $\mathrm{Al}_{\mathrm{x}} \mathrm{Ga}_{1-\mathrm{x}}$ As ternary barriers from the following expressions

$$
\begin{aligned}
& \tan \left[\frac{a}{2 \bar{h}}\left(2 m_{a} E_{\text {min }}\right)^{1 / 2}\right]-\left[\frac{m_{a}}{m_{b}}\left[\frac{V}{E_{\text {min }}}-1\right]\right]^{1 / 2} \\
& \tan h\left[\frac{b}{2 h}\left[2 m_{b}\left(V-E_{\text {min }}\right)\right]^{1 / 2}\right]=0 \\
& \tan \left[\frac{a}{2 \bar{h}}\left(2 m_{a} E_{\max }\right)^{1 / 2}\right]-\left[\frac{m_{a}}{m_{b}}\left[\frac{V}{E_{\max }}-1\right]\right]^{1 / 2} \\
& \cot h\left[\frac{b}{2 \bar{h}}\left[2 m_{b}\left(V-E_{\max }\right)\right]^{1 / 2}\right]=0
\end{aligned}
$$

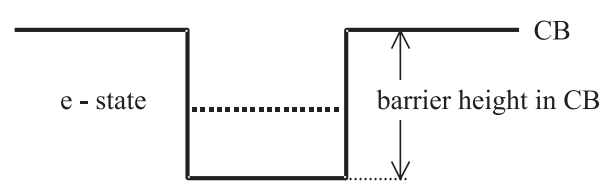

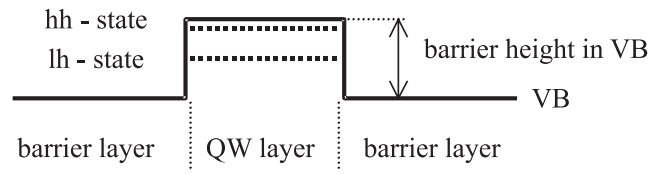

Fig. 2 Quantum confined e, hh and lh energy states. Square potential well for electrons and holes is formed by material parameters $\left(E_{g}, V B O\right)$ and thickness of $Q W$ layer.

where $a$ and $b$ are well and barrier thickness and $m_{a}$ and $m_{b}$ the particle effective masses inside $\mathrm{QW}$ and barrier, respectively. The energy $E$ of localized particle states $(e, h h, l h)$ is calculated from the minima of conduction and valence band, respectively. The barrier height $V$ of conduction and valence band is determined from the valence-band offset of well and barrier materials [9]. These expressions are generally valid as well for QW structures as for superlattices, where in superlattice structures with thin barrier layer the solution of particle energy splits into minibands represented by an energy range $\left(E_{\max }-E_{\min }\right)$ [3]. The energy states of higher order $(n>1)$ in CB and VB can be determined similarly according to [8].

\section{Laser preparation}

The sample growth was carried out by low-pressure MOVPE in a commercial AIXTRON AIX-200 reactor equipped with a rotating substrate holder and standard precursors TMAl, TMGa, TMIn, DetZn, $\mathrm{AsH}_{3}$ and $\mathrm{Si}_{2} \mathrm{H}_{6}$ with vapor pressure values $p(t o t)=50$ mbar and $f(t o t)=7 \mathrm{slm}$ on $(001)$ oriented n-type GaAs substrates. The MOVPE experiments were carried out at growth temperatures $700{ }^{\circ} \mathrm{C}$ [1]. The layer arrangement (Fig. 3a) consists of a $450 \mathrm{~nm} \mathrm{GaAs}$ buffer layer followed by a $1300 \mathrm{~nm}$ n-doped $\mathrm{Al}_{0.55} \mathrm{Ga}_{0.55} \mathrm{As}$ confinement layer, the active region and $550 \mathrm{~nm}$ p-doped $\mathrm{Al}_{0.55} \mathrm{Ga}_{0.55}$ As. The structures were covered by $10 \mathrm{~nm} \mathrm{GaAs}$ layer. The active region contains 10 spatially well-separated InAs monolayers buried in thick $(20 \mathrm{~nm}) \mathrm{Al}_{0.40} \mathrm{Ga}_{0.60} \mathrm{As}$ barriers. The contact metalization was performed by evaporating $\mathrm{Au}$ on top GaAs layer and AuGeNi on the bottom of $n+$ GaAs substrate.

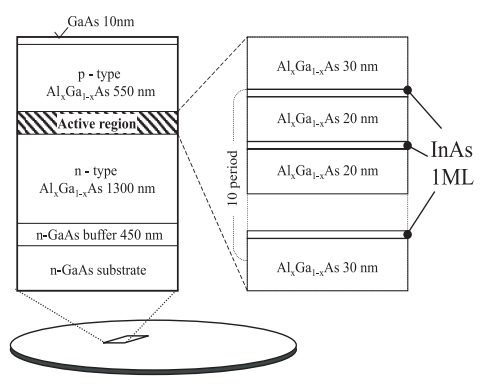

a)

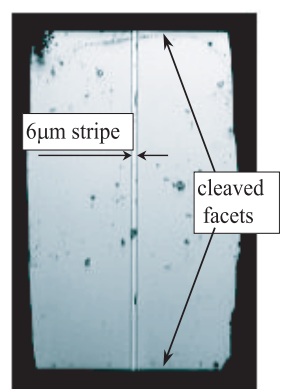

b)
Fig. 3 a) The layer arrangement of $Q W$ structure with detail of InAs/Al $\mathrm{Ga}_{1-x}$ As active region. b) CCD surface image of stripe laser device. The spontaneous emitting light arises in InAs $Q W$ and is amplified between cleaved planes along the Au stripe contact.

For the emission study the gain guided metal stripe lasers were fabricated. The stripes width of $6 \mu \mathrm{m}$ in $\mathrm{SiO}_{2}$ mask and $\mathrm{AuBe} / \mathrm{Ti} / \mathrm{Au}$ p-contact layer were prepared. The laser device fabrication was completed by thinning the wafer to $150 \mu \mathrm{m}$ thickness and evaporation of bottom $\mathrm{AuGe} / \mathrm{Au}$ n-contact. The samples were cleaved perpendicular to metal stripes (Fig. 3b). From the Kronig-Penney model the energy of optical transition was calculated to be 1.973 $\mathrm{eV}$ at $T=0 K$. As Kronig-Penney inputs the InAs $/ \mathrm{Al}_{0.40} \mathrm{Ga}_{0.60} \mathrm{As}$ material and layer thickness parameters according to the schematic in fig. 3a were used.

\section{Experimental results}

The electrical and optical properties of prepared laser device based on MQW structure were investigated. Electrical properties were examined by current-voltage measurements at forward bias. From room- and low-temperature electroluminescence (EL) measurements the optical properties were revealed. The low-temperature EL spectra were measured in He-close cycle cryostat. For recording the EL spectra monochromator of type SPM2 and Siphotodetector were employed. The EL intensity vs. driving current was measured by conventional pulse technique. Laser mode emission spectra were recorded using high-resolution double grating monochromator.

\section{Electrical properties}

The current-voltage measurement at forward bias shows the $\mathrm{p}$-n junction opening in the range of $1 \mathrm{~V}$ in correspondence with diffusion potential. The weak edge emission from the active region was observed at current about $1 \mathrm{~mA}$. The current flow increasing through the MQW region has influence on emission intensity. 
The current flow is limited in the range of $1.5 \mathrm{~V}-2.5 \mathrm{~V}$ due to low conductivity of confinement layers and intrinsic MQW active region as shown in current-voltage dependence (Fig. 4).

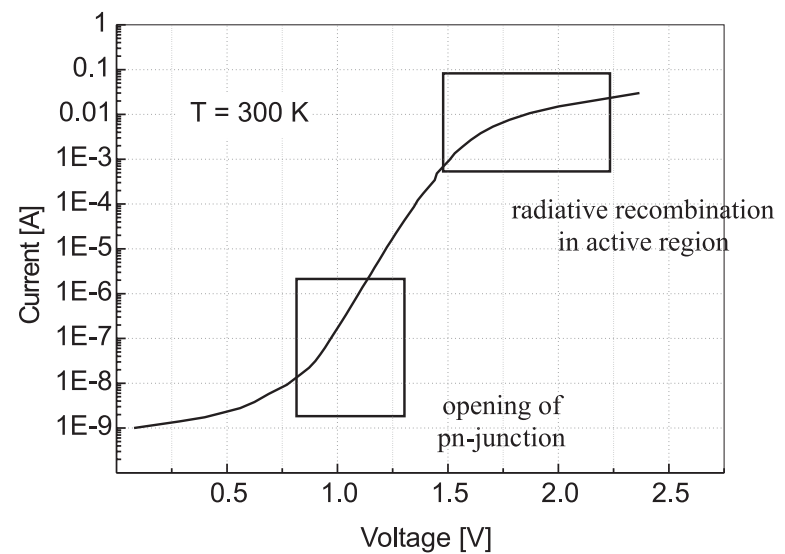

Fig. 4 Current-voltage dependence of laser device. Room temperature spontaneous emission starts at driving current app. $1 \mathrm{~mA}$.

\section{Optical properties}

The optical properties on stripe laser structures were investigated by measuring the room- and low temperatures EL spectra from the cleaved edge of laser structure.

Room temperature EL spectrum revealed only the weak spontaneous emission from the cleaved edge of the laser structure with maximum intensity at $1.891 \mathrm{eV}(655.7 \mathrm{~nm})$ (fig. 5a). When going to low temperatures a considerable increase of the EL intensity (Fig. 5b) due to the strong localization of bound states in QW was observed and the energy of main maxima shows the blue shift in correspondence with $E_{g}(T)$ relation of $\mathrm{Al}_{\mathrm{x}} \mathrm{Ga}_{1-\mathrm{x}}$ As barrier. At $T=$ $=20 \mathrm{~K}$ the maximum intensity lies at the energy $1.995 \mathrm{eV}(621.6$ $\mathrm{nm})$.

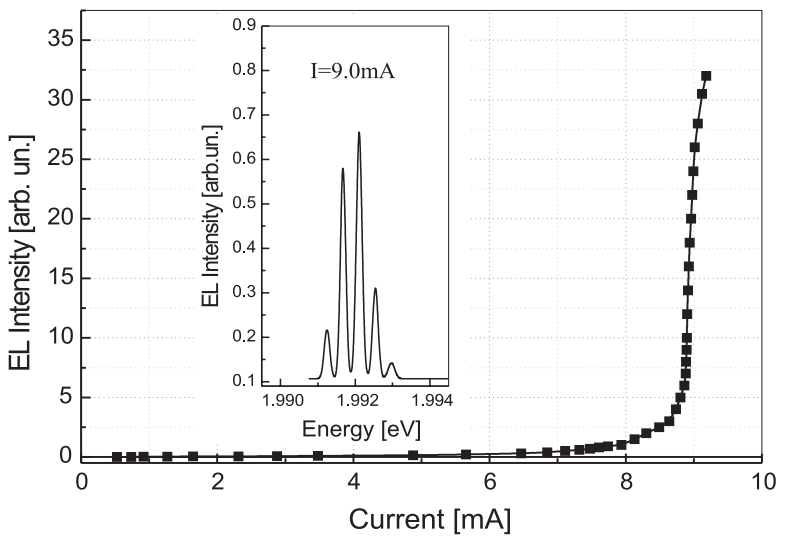

Fig. 6: The EL intensity vs. driving current and laser mode spectra (insert figure) of laser device based on InAs $/ \mathrm{Al}_{0.40} \mathrm{Ga}_{0.60} \mathrm{As}$ $Q W$ structure in active region.

From comparison of the experimental results and theoretical predictions $(1.973 \mathrm{eV}-T=0 \mathrm{~K})$ from point of view of the main peak energy position in EL spectra, the small discrepancy (app. $20 \mathrm{meV}$ ) was found. It could be caused probably by replacing the real structure by periodic square potential in Kronig-Penney model as well as exciton binding energy of localized e-hh pairs (excitons) in QW [7].

To achieve the higher emission energy the $\mathrm{Al}_{0.40} \mathrm{Ga}_{0.60} \mathrm{As}$ was used in active region. Thus, the emission energy increased of

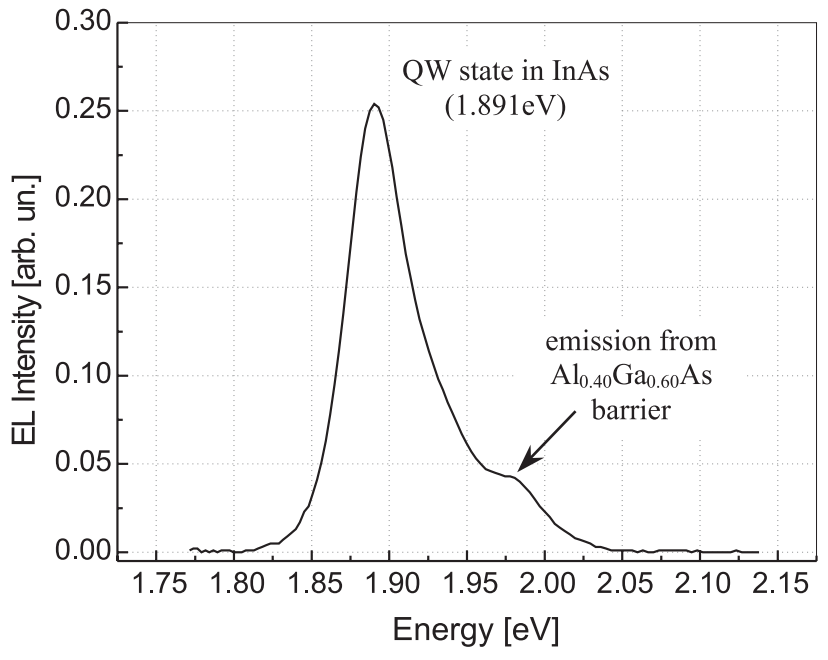

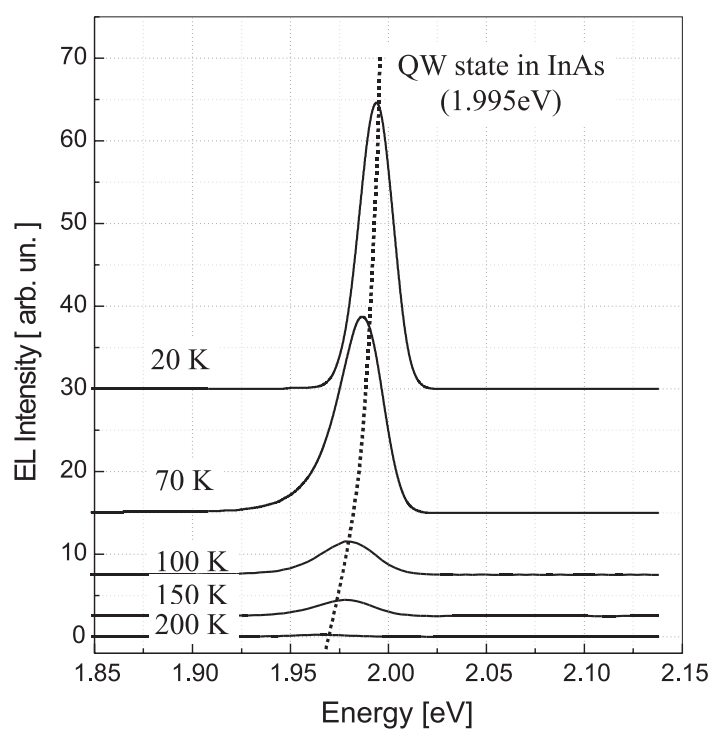

b)

Fig. 5 The EL spectra recorded from the cleaved edge of laser devices at a) room temperature and b) in temperature range of 20 - 200K. Dashed line shows the blue shift of maxima. 
app. $80 \mathrm{meV}$ in comparison with the structures employing the $\mathrm{Al}_{0.33} \mathrm{Ga}_{0.67} \mathrm{As}$ material in active region [7, 9].

For the temperatures ranging from $20 \mathrm{~K}$ to $100 \mathrm{~K}$ the prepared stripe laser structure with InAs monolayers shows stimulated emission across their cleavage planes. The EL intensity vs. driving current characteristic of this structure shows the typical increase of emission intensity in the region of threshold current density (Fig. 6). Insert figure shows a laser mode spectrum measured at $T=20 \mathrm{~K}$ and driving current $9.0 \mathrm{~mA}$. From the recorded dependence the extremely low threshold current and current density was estimated to be $I_{t h}=8.9 \mathrm{~mA}$

\section{Conclusion}

To sum it up, we studied the optical and electrical properties of MQW structures based on InAs/ $\mathrm{Al}_{\mathrm{x}} \mathrm{Ga}_{1-\mathrm{x}}$ As materials grown by MOVPE as a real perspective structure for applications in laser devices. Optical properties were investigated by current and temperature dependencies of EL spectra taken from the cleavage plane of stripe laser arrangements.

Room temperature EL spectrum shows only weak edge emission at energy $1.891 \mathrm{eV}$. At low temperatures $(20 \mathrm{~K}-100 \mathrm{~K})$ the
InAs monolayer luminescence becomes very sharp and intense; its peak energy reflects nearly the $E_{g}(T)$-relation of the $\mathrm{Al}_{\mathrm{x}} \mathrm{Ga}_{1-\mathrm{x}} \mathrm{As}$ band gap [10]

In the low temperature range stimulated emission for investigated structures occurs at photon energies of about $1.995 \mathrm{eV}$ $(621.6 \mathrm{~nm}$ ) for $T=20 \mathrm{~K}$. At higher temperatures (above 100K) the stimulated emission disappears due to the thermal dissociation of InAs monolayer-bound excitons [2].

The material and layer parameters for growth processes could be calculated by simple Kronig-Penney model.

In our opinion the material system under investigation might be interesting for potential optoelectronic device applications. These excellent emission properties observed in MQW structures with the material basis of InAs $/ \mathrm{Al}_{\mathrm{x}} \mathrm{Ga}_{1-\mathrm{x}}$ As could be successfully employed in possible applications in the light emitting and laser devices operated in red and orange-red range of spectra.

\section{Acknowledgement}

This work has been supported by Slovak Grant Agency contract No.7600/20, International Laser Center Bratislava and bilateral WTZ project No. SVK01/001 (21/2001).

\section{References}

[1] GOTTSCHALCH, V., SCHWABE, R., WAGNER, G., KRIEGEL, S., FRANZHELD, R., PIETZONKA, I., PIETAG, F., KOVÁČ, J. Proc. of 7th EW MOVPE, June 8-11, Berlin, 1997, E4

[2] TRAN, C. A., ARES, R., KARASYUK, V. A., WATKINS, S. P., LETOURNEAU, G., LEONELLI, R.: Phys. Rev. B 57, 1997, pp. 4633-4638

[3] MUKHERJI, D., NAG, R.B.: Phys. Rev. B 12, 1975, pp. 4338-4345

[4] IOTTI, R. C., ANDREANI, L. C., VENTRA, M. D.: Phys. Rev. B 57, 1998, pp. 15072-15075

[5] KOVÁČ, J., KUNA, L., GOTTSCHALCH, V., BENNDORF, G., GERHARDT, M., PUDIŠ, D., JAKABOVIČ, J., ŠKRINIAROVÁ, J.: Proc. of 8th EW MOVPE, June 8-11, Berlin, 1999, F1M4

[6] BITZ, A. J.: Ph.D. thesis, 1997

[7] PUDIŠ, D., KOVÁČ, J., KOVÁČ, J.,jr., JAKABOVIČ, J., GOTTSCHALCH, V., BENNDORF, G., RHEINLÄNDER, B., SCHWABE, R.: Advances in Electrical and Electronic Engineering 1, 2002, pp.33-37

[8] CHO, H. S., PRUCNAL, P. R.: Phys. Rev. B 36, 1987, pp. 3237-3242

[9] CATAlano, I. M., CINGOlani, A., LePORE, M., CINGOlani, R., PlOOG, K.: Phys. Rev. B 41, 1990, pp. 12937-12940

[10] BLAKEMORE, J. S.: J. Appl. Phys. 74, 1993, pp. R123-R181 